Review Article

\title{
Role of $5 G$ and Artificial Intelligence for Research and Transformation of English Situational Teaching in Higher Studies
}

\author{
Haojie $Y u^{1}$ and Shah Nazir (D) $^{2}$ \\ ${ }^{1}$ Department of Fundamental Courses, Basic Department, Yantai Vocational College, Yantai, Shandong 264670, China \\ ${ }^{2}$ Department of Computer Science, University of Swabi, Swabi, KP, Pakistan \\ Correspondence should be addressed to Shah Nazir; shahnazir@uoswabi.edu.pk
}

Received 22 October 2021; Accepted 11 November 2021; Published 26 November 2021

Academic Editor: Hasan Ali Khattak

Copyright (c) 2021 Haojie Yu and Shah Nazir. This is an open access article distributed under the Creative Commons Attribution License, which permits unrestricted use, distribution, and reproduction in any medium, provided the original work is properly cited.

\begin{abstract}
We live in a modern and technological society run by intelligent and human-like machines and systems. This is due to the advancements in the field of artificial intelligence. The machines are directly or indirectly used in different sectors like healthcare, automatic vehicles, and complex decision-making and at the same used in educational institutes. The usage of AI-based systems and the Internet has brought numerous educational innovations for both teachers and students. With the online learning platforms grounded on AI techniques, $5 \mathrm{G}$ has revolutionized the teaching and learning methods by smooth and faster access to educational content. Students of foreign languages, especially English learners, can now use chatbots and intelligent tutoring systems to learn and practice their speaking and listening skills offline and online. With Computer-Assisted Language Learning (CALL), the English learning process can now be interactive and productive. The students can now improve their language skills by conversing with AI-based agents instead of native speakers to avoid any fear and anxiety. The intelligent platforms can understand the consuming power of the student and hence can create and give content according to their level to create an individualized learning environment. With the help of digital assistants, people can also find it very easy and productive to improve English proficiency. To accomplish the goal of English teaching very easily and ideally, the teachers should use AI-based techniques in the classrooms. With the help of intelligent assistants for the daily workload of a teacher, we will be able to concentrate fully on the language learning and skills of the students. The current study has presented a detailed overview of 5G and AI's role in research and transformation of English situational teaching in higher studies. The search results are compiled and presented with different details of the area.
\end{abstract}

\section{Introduction}

Intelligent and human-like machines and systems run modern-day society. This is due to the progressions and developments in the field of artificial intelligence. The devices are used in diverse areas like healthcare, automatic vehicles, and complex decision-making and at the same used in educational institutes. Researchers are endeavoring to come up with solutions that deal with modern-day issues. Lee and Kim [1] have proposed a study for the impact of 5G in university education based on specific parameters like learning space, content and time, etc. The experiments were performed on 102 students, and they ranked every parameter according to their opinion and use. About $86 \%$ of them were in favor of using $5 \mathrm{G}$ in education. The students want to study by the use of intelligent devices and valuable materials. They do not wish to be bound by the constraints like time and place. Therefore, it is required to speed up the use of $5 \mathrm{G}$ in university education to improve it and make it available at a low cost. Al-Maroof et al. [2] have proposed a study on various factors directly related to the use of $5 \mathrm{G}$ in the Gulf area. The findings show that with cheapness, faster speed, and high quality, Internet usage can be increased by $5 \mathrm{G}$. It can be used in education for the purposes like e-learning and content sharing by teachers and students faster and efficiently. The acceptance rate of $5 \mathrm{G}$ is very high due to faster speed and rapid data broadcast. Its easiness of use and effectiveness can bring very positive change in the 
daily life human race. Lei [3] has proposed an optimization strategy to overcome the difficulties and hardships in college English learning in China. With 5G and AI, the English classrooms are now intelligent and efficient for learning college English. With the teaching methods of AI and 5G integration, it will be made possible that the students will be provided knowledge according to their level and skills. The strategy will improve the reading, writing, listening, and speaking skills and abilities of students.

Gao [4] has proposed a study in the era of $5 \mathrm{G}$ to find out the applications of modern technology in English major in one of the universities of China. Due to the faster transfer rate and numerous valuable online resources, it is very beneficial in teaching English to help students find appropriate content easily and without any constraints. Most universities provide online courses, and the students can select from them according to their requirements. The usage of $5 \mathrm{G}$ in the development of education will be a milestone in human history. Islam and Hasan [5] have presented a study to explore the effectiveness of mobile-assisted language learning in listening skills for both teachers and students and to find out the enhancement due to the use of mobileassisted language learning (MALL) in language learning. The use of mobile in teaching and learning English is widespread in our daily lives. The findings show that it is very effective and efficient to use mobile-assisted language learning in learning English. MALL has enabled the students to get e-materials and different available applications to improve their grammar and expressions. As a result, they are speeding up the process of learning English.

Samigulina and Shayakhmetova [6] have proposed a study to develop an intelligent system based on deep learning for visually impaired people to get benefits from distance education. The system can process data from diverse dimensions, understanding the perception and consciousness knowledge evidence of visually impaired persons. The vital module of the intelligent system consists of statistics, intelligence, knowledge, and controller block. The materials are provided based on a questionnaire analyzed with the help of fuzzy logic. With the proposed model, the VIP can exploit the educational assets in a very effective way. Chung and Kim [7] have presented a survey to show the opinion and user's acceptance of artificial intelligence as a lecturer in university class by young adults. For the collection of data to be examined, interviews and questionnaires were used. It was predicted that some adult students were in favor of AI-based lecturers in e-learning. In the opinion of some students, it is good to use AI lecturers in class, but they should be managed directly by a human. The fact was found that there is no relation between loneliness and artificial intelligence of the students. Some views show that a good and positive relationship is also probable with the intelligent-based lecturer. Obari and Lambacher [8] have proposed a study to examine the effect of Google Home Mini and Amazon Alexa grounded on artificial intelligence on the English improvement and learning skills of a private university in Japan. Tests were taken before and after the training of the concerned groups. The results show that a mixture of AI with blended learning has a positive and impressive effect on teaching a student's English language. With the help of this integration, the speaking and listening skills of the students were also improved. The students were in favor of using AI-based speakers with blended learning technology.

The current study effort is to present detailed reviews of the existing literature in the following manner:

(i) To present literature on the implications of AIbased classroom and AI-based humanized lecturer

(ii) To show details of the creation of intelligence-based learning path and study on computer-assisted tutoring systems

(iii) To analyze the role of 5G network technology and artificial intelligence for English situational teaching in higher studies from different perspectives, like details of the publications in the given libraries

The structure of the paper is given as follows. Section 2 describes the implications of the AI-based classroom. Literature on the AI-based intelligent humanized lecturer is given in Section 3. Section 4 shows the creation of an intelligence-based learning path. Details of the computerassisted tutoring systems are given in Section 5. Section 6 shows the role of $5 \mathrm{G}$ network technology and artificial intelligence for English situational teaching in higher studies. The paper is concluded in Section 7.

\section{Implications of AI-Based Classrooms}

The study has presented a system for nonnative English learners to improve their listening and speaking skills with the help of a virtual environment integrated with artificial intelligence. The system is capable of keeping track of the learning activity of the user and assessment of the user. The findings show that the appropriate responses were amplified by 14 percent, while the linguistic mistakes were lessened by three percent. The overall learning proficiency was sped up by 11 percent. The speaking period was reduced by 16 percent [9]. Keerthiwansha [10] has focused on employing artificial intelligence-assisted systems in English as a second language (ESL) in Sri Lanka. The system is capable of increasing the effectiveness and productivity of ESL classes. Due to the individualized learning path and no constraints of space and time, the proposed architecture provides a peaceful and fruitful environment. The students who missed the lesson in class will be able to attend it at home. Due to low documentation work, all the energy will be used in teaching and learning procedures. At the back of the system, there is a controller to manage all the activities of artificial intelligence education (AIEd). Zhu [11] has proposed a study to develop and improve intelligence-based English classrooms to decrease the burden and increase the productivity of English teaching and learning. By using the interface of the proposed system, the teacher can arrange video classes and assess the students with the help of data technology. To check their skills and knowledge, the students can solve exercises and check their learning levels. With the development of AI-based applications, we can lead the English 
learning process in a positive direction. Adamopoulou and Moussiades [12] have proposed a study on the applications and improvement of chatbots and the technology used to improve performance and make it bright. In the field of education, they have surpassed the teachers and are available to students. The vital role of chatbots in the view of users is productivity, along with social interaction and innovations. The users can experience an amicable and fruitful environment while communicating with the chatbots. The English learners can now communicate with chatbots and improve their speaking and listening skills and knowledge.

Okonkwo and Ade-Ibijola [13] have proposed a review based on previous approaches to using chatbots in education. It was predicted that they could be used for different purposes in education like teaching, learning, and administration. For teaching purposes, it can be used to teach online courses to students, while as an administrative component, it can be used to reply to students' queries related to the study. The use of chatbots can achieve the productivity of education and convincing of students. With the help of AI-based intelligent systems, many students can be dealt with from various locations. Al-Mohammadi et al. [14] have proposed a survey for the use of AI-based intelligent systems in e-learning for adaptive educational atmosphere and different techniques used to make the e-learning process more intelligent. For a productive adaptive atmosphere, the use of AI-based technology is essential. They have the capability to replicate human decision and cognitive skills; they can grip any unwanted situation and improve the development of processes for an effective learning environment. For adaptive learning, individual learning is an important factor, which can be acquired through AI techniques. Kucak et al. [15] have proposed a study on the role of machine learning technologies and their current and future applications in education. The findings show that with the help of ML, the faculties can reach the students within no time. The student's knowledge and skills can be predicted very easily and efficiently with the use of machine learning algorithms. One can identify the weak areas of students and different ways to improve them. With the ability to continuously comment about the students' performance, the teachers and parents are aware of their current progress at any time. Kulkarni et al. [16] have presented a chatbot to handle a customer's queries in a bank and provide them with a suitable solution. They can provide their query in Simple English, and the system will efficiently resolve the issue. The customer will be provided with the same service environment with one variation that there will be an AI-based robot system instead of a human being. Due to the fast working of bots, the system will be beneficial to both bank and customer in time-saving. The system will be able to decrease the burden from humans, increase the effectiveness, and have a large number of convincing customers.

\section{AI-Based Intelligent Humanized Lecturer}

Nalyvaiko and Maliutina [17] have proposed a study to find out the use of chatbots by the students of higher educational institutions (HEI) and their role in the procedures of HEIs.
Due to the advancement in information and communication technology, people are more attracted to interactive platforms. The young generation prefers smart devices over books. Therefore, there is a need to develop and optimize the learning process with the help of chatbots. In the opinion of about 63 percent of respondents, using chatbots in the education process is very effective and beneficial. About 2 percent of participants are not in favor of chatbots. Arain et al. [18] have proposed a study to develop a chatbot that consists of three interfaces for the examination section of Mehran University. The bot will help in addressing multiple students at a time and hence can save their time. By comparing all the interfaces, it was predicted that due to convenience, usability, and general acceptance, the English keying grounded interface is best to be used. The chatbot can give responses in both written and speaking forms to the queries of the users. It will be beneficial in speeding up the examination activities. Hsu et al. [19] have presented a chatbot for English learners to practice English speaking with an online system called TPBOT to remove their fear of speaking English. The results show that it is a very effective and productive tool for oral English learning. The students who participated in the experiments have greatly increased their oral skills. The system is capable of providing on-the-spot assessment and provides constructive responses. It will help the learners to learn oral English without any uneasiness due to practicing with human native speakers. Petrovic and Jovanovic [20] have proposed a study on chatbots as language learning agents and the forthcoming encounters in this area. Chatbots play a very vital role in the learning process of English learners. It can provide learners with a variety of vocabulary, different syntax, and semantics. They are capable of learning from humans through professional management and hence can seizure the development of languages. With the help of AI-based techniques for text and voice recognition, the chatbot can be equipped with more incredible technology. Noviyanti [21] has proposed a study for finding out the positive impact of pronunciation learning with the help of a pronunciation inspector based on artificial intelligence. A questionnaire was used to check the views of students about the system, a. The result shows that the oral communication of the students has been improved very well. In the opinion of the students, the use of AI-based technologies is beneficial in pronunciation, but this process can be made faster if they can practice oral English with human native speakers.

Phobun and Vicheanpanya [22] have presented a combination of an artificial intelligence-based system with an adaptive learning environment. The system helps make the available knowledge independent of different constraints and makes the students' e-learning more interactive and fruitful. For better delivery of thoughts, the use of Adaptive Hypermedia $(\mathrm{AH})$ is very essential while artificial intelligence-based tutoring systems improve the problem-solving skills with these thoughts. $\mathrm{AH}$ and the intelligent tutoring system (ITS) are playing a very important role in learning based on computers. The proposed system is the combination of both of these systems. Rahimi and Fatemeh Hosseini [23] have proposed a study to find out the opinion of high school students of Iran on the use of the artificial 
intelligence-based system for learning foreign languages. The results show that after the training, the students are in favor of using computer-assisted technologies for learning languages. They have a positive attitude toward the environment of computers, artificial intelligence-based exercises, and assessments. With the use of computer and information technologies, the students are able to increase their confidence level and make a positive attitude toward its friendly environment. However, the overall trust in the computer is dependent on the training of the participants. Shafaei [24] has proposed a study in order to find out the effectiveness of artificial intelligence-assisted technologies in learning English for universal learners in Malaysia. The system has a positive impact on the opinion of students to learn from computer-based technologies. It plays a vital role in making grammar easy to understand and learn. Students are more at ease while learning and practicing with the proposed system. The teachers should integrate the use of computer technologies with traditional teaching to make the learning process more interesting and productive. Kose and Arslan [25] have proposed a study to find out the applications and procedures of computer-assisted systems in language education courses. The system is used for the same time in Turkey, Italy, and Romania. The findings of the usage show that the proposed system is very useful in the increasing and development of the learning process. With the same model and architecture, the system can be used by students of different countries. In the opinion of the learners, the software is very helpful in their classroom to achieve the goal of learning the language. The assessment system of the proposed technology is also very effective. Azzi et al. [26] have proposed a study in order to know the learning style of the learners and provide the contents according to it. For the reading of students' education conduct, the web usage mining is used, and then the recorded data is mapped with Felder-Silverman Learning Style Model. Fuzzy C Means algorithm was used to make clusters from the recorded information. Knowing of user's learning environment is essential for the easy, timely, and fruitful understanding of the provided content from the learners. It is also helpful for the teachers to decide which teaching method is very effective and productive for the particular online session.

\section{Creation of Intelligence-Based Learning Path}

Kolekar et al. [27] have proposed a study to find out the user's learning style by the activities or navigations that the user is performing on the online learning system. The proposed approach has used ANN of machine learning and web usage mining. The suggested procedure work on the history of the system, hence, can detect any change in the design and record the recent learning behavior of the enduser. The content of the online system should be adapted according to the requirement of the end-users. Due to the unique learning nature of every student, the teaching method affects the outcome in one way or the other way. Meng-Yue et al. [28] have proposed a system for using artificial intelligence-based systems to teach college English culture and create unique opportunities for students to learn
English culture effectively. With the use of artificial aided design, the teaching and learning environments can be promoted and advanced. They can be used to learn about English culture in a very positive manner. In college English teaching, the integration of machine learning with the curriculum can bring innovations in the teaching and learning process. The proposed system is the combination of AI, ML, DL, and big data. With the usage of artificial intelligence, it is easy to provide the students of English culture with good quality of knowledge. Yuan [29] has discussed the artificial intelligence-based technologies in college English learning, their applications, and innovations in the field of English education to design an effective college English teaching. With the implementation of AI in education, the students learning skills have been enhanced and very helpful in achieving the goal of English learning. The survey related to the proposed system shows that about $92 \%$ of learners favor using computer-assisted machines in the process of English learning. The students also prefer teaching methods based on the use of advanced information and communication technology. Due to advancements in artificial intelligence, many applications have been developed to improve and reform current college English teaching. Sun and Li [30] have introduced artificial intelligence and big data into the English learning atmosphere to make it productive and meet the needs of social development. The result of the system shows that the proposed system will play a vital role in developing a method of teaching and knowledge materials. With the comparison of some existing techniques, the application ability of English is improved. Compared to old teaching methods, the suggested one has better consequences on students' performance and interest. With the mutual bond of artificial intelligence and big data, the current system has provided a suitable direction for gaining knowledge of the English language.

Che et al. [31] have proposed an IoT wearable system grounded on artificial intelligence to use human-computer interaction in college schooling. The system can get data from the remote storage as per the user's requirement and then perform some computations on that data with the help of artificial intelligence. It is very easy for the students to practice and educate themselves to use the proposed wearable device without any trainer. The suggested system is very effective in the assessment of athletes during fieldwork or exercises. Due to the selection of data according to the condition of each student, the system can handle everyone independently. Nabiyev et al. [32] have proposed a method for improving the skills of students in mathematics and improving the use of artificial intelligence in distance learning. The survey findings show that the system is functional and is very productive in solving different mathematical problems. There is a need for some abstract alterations. More questions can be added to the system in the teacher module of the system. In the view of students, the system helps increase the knowledge of solving a specific problem and an understanding of it. It is necessary to make a habit of solving a specific problem in a stepwise manner. The students can discuss and communicate with one another to solve the exercise. Dong and Tsai [33] have proposed an 
architecture grounded on fuzzy neural network (FNN), and the techniques of computational technologies are applied to make an interactive for learning English. The system automatically performs functions like score calculation, making an individual's learning plan, and making quantitative approaches for sentences. With the suggested method, some deficiencies like reciting words and many more are removed from the old-fashioned English learning. The system will improve the learning skill of students by providing them with the learning environment according to their requirements. The thesaurus used in the proposed approach is taken from a free public source. With the use of the neural network, the intelligence of AI-based technologies is increased very much. Chen and $\mathrm{Li}$ [34] have proposed an architecture of adaptive English vocabulary learning based on the location of the user recorded with the help of wireless techniques, learning with time, and the individual capability of learning to support the students in understanding the vocabulary of the English language. The experiment's findings show that people using PCULS have better speech performance than those without background responsiveness. The system can get the location of the user up to $92 \%$ accuracy. With the help of PDA, the system is implemented for practical use without any restrictions of space and time. About $72 \%$ of people are in favor of using the system with the concept of background awareness.

\section{Computer-Assisted Tutoring Systems}

Muhammad et al. [35] have proposed a chatbot based on artificial intelligence and speech recognition to help the users improve and advance their English speaking ability. With the advancement in information and technology, intelligent devices are used in everyday life. People are using these smart devices to learn languages, and dependence on these devices is increasing day by day. Expert opinions were used to find out the goal completion of the proposed system and the views of people toward the effectiveness of the chatbot. The findings show that the system is $100 \%$ effective and productive in the learning process. It will help the students to improve their speaking skills. Sung [36] has proposed a study to examine the performance of artificial intelligence-based English speaking chatbots. The two groups that were analyzed have made two systems. One is behaving like a new friend while the other is responding in particular conditions. The experiment's findings show that it is a valuable time for the students to interact with the chatbots playfully and adaptively. The student's communication sessions with the systems can improve their speaking and listening skills and build their confidence level. It is also identified that using artificial intelligence-based systems can help the learners of foreign languages to learn and advance their knowledge about the conversation of a particular language. Liu [37] has proposed a study to find out the positive impact of language teaching through IB-MALL in the opinion of students in China. The students with no English background are facing a lot of difficulties in China in their English learning. For the excellent survey and data collection, both quantitative and qualitative analyses are carried out. In the students' views, by using the proposed system, their command of English speaking and listening is improved, but their other skills are also developed. From the recorded data, it was found that almost all the students favor the proposed system and show their acceptance toward Internet-based Multimedia Assisted Language Learning (IBMALL). Some of the students have also provided valuable proposals for more applications and advancement of IBMALL.

Cuiye [38] has proposed a study on the combination of artificial intelligence-based applications and English teaching to solve the problems and difficulties in the old-fashioned way of English learning. The proposed research focused on building and developing of intelligent and personalized teaching atmosphere to develop the skills and effectiveness of English teachers. With the positive exploitation of computer-assisted and NLP implications, the overall language learning classroom has been improved along with the students' learning power development. The findings show that the advancement of computational techniques in the teaching process has brought innovations in the education process. Huang [39] has proposed an English tutor robot for getting innovations and development in English teaching due to advancement in artificial intelligence-based systems. Based on the proposed approach, the curriculum is practiced in primary school in English, and the results were very effective and impressive. It was analyzed that the suggested system can perform the routines of English vocabulary teaching and improve the ability and interest of students in learning English. The curriculum based on the robot is more accurate and fast in completion of the goals and the novelty of the teaching method. The system is very effective in further improving and innovating the educational process. Liu and Kong [40] have proposed a study to examine the incorporation of artificial intelligence-based systems with English teaching to create a productive, improved, and effective atmosphere in the framework of intelligent computational techniques. The design of computerassisted learning procedures is helping in making a new model of teaching, which will bring innovation in the area of English teaching and learning. It will be continuously updated with the help of the integration of new components. With the proposed system, the teaching model will be shifted from teacher-centered to student-centered and will help develop the language skills and cultivate other intelligence in the students. Lai and Kritsonis [41] have proposed a study to analyze the pros and cons of the implementation of computer-assisted and artificial intelligence-based systems in the process of learning a second language. Due to many people with LEP, it is of great importance to successfully exploit information technology and artificial intelligence along with natural language processing to improve the English proficiency of these people. The implementation of AI and CALL is now widespread and generic in the process of learning foreign languages. It was examined that with the help of these advanced technologies, English learning can be made very interesting and productive. The main disadvantage of these systems is the unawareness of teachers and students from the use of it and economic and loneliness. 
TABLE 1: Methods used in the literature related to the current research.

\begin{tabular}{|c|c|c|}
\hline Reference no & Method & Year \\
\hline [51] & Online intelligent English teaching & 2021 \\
\hline$[52]$ & An English network teaching & 2021 \\
\hline$[53]$ & Perceptions on the impact of AI on English language learning & 2021 \\
\hline$[54]$ & Chatbots in education & 2021 \\
\hline$[55]$ & Network intelligent control and traffic optimization & 2021 \\
\hline [4] & Educational technology in English major college teaching & 2021 \\
\hline [2] & Acceptance determinants of $5 \mathrm{G}$ services & 2021 \\
\hline [13] & Chatbots applications in education & 2021 \\
\hline [19] & Task-oriented chatbot system & 2021 \\
\hline [17] & Chatbots in higher education & 2021 \\
\hline$[31]$ & Human-computer interaction on IoT-based college physical education & 2021 \\
\hline [43] & College English teaching innovation under AI & 2021 \\
\hline [33] & Machine learning and neural network in English learning & 2021 \\
\hline [39] & Educational robot teaching resources using AI & 2021 \\
\hline [40] & College English teaching mode based on AI & 2021 \\
\hline [47] & Vocabulary intelligent tutoring system for second-grade latinx English learners & 2021 \\
\hline$[56]$ & Understanding students' perceptions of AI teaching & 2020 \\
\hline [57] & AI-enabled routing in software-defined networking & 2020 \\
\hline [1] & Innovation in university education & 2020 \\
\hline [5] & Mobile-assisted language learning & 2020 \\
\hline [7] & Adult learners in distance education & 2020 \\
\hline$[12]$ & Chatbots & 2020 \\
\hline$[20]$ & Conversational agents for learning foreign languages & 2020 \\
\hline [21] & AI-based pronunciation checker & 2020 \\
\hline$[26]$ & Prediction of learning styles in adaptive e-learning & 2020 \\
\hline$[30]$ & Eco-environment construction of English teaching using AI & 2020 \\
\hline [3] & The strategy of college English mode based on $5 \mathrm{G}$ and AI & 2020 \\
\hline [35] & Chatbot using dialogflow & 2020 \\
\hline$[36]$ & Preservice primary English teachers' AI chatbots & 2020 \\
\hline$[58]$ & AI chatbot as a language learning medium & 2020 \\
\hline$[28]$ & College English culture intelligence-aided teaching & 2020 \\
\hline [49] & $\mathrm{AI}$ in EFL context & 2020 \\
\hline$[50]$ & AI in education & 2020 \\
\hline [59] & AI writing evaluation system in China CET & 2019 \\
\hline$[60]$ & AI promoting English learning change & 2019 \\
\hline$[61]$ & Foreign language education in the era of AI & 2019 \\
\hline$[62]$ & AI applications in higher education & 2019 \\
\hline$[63]$ & AI chatbots for improving English grammar skills & 2019 \\
\hline$[8]$ & English skills of native Japanese using AI & 2019 \\
\hline$[42]$ & AI-based student bot for academic information system & 2019 \\
\hline$[48]$ & Voice assistants and AI in education & 2019 \\
\hline$[37]$ & IB-MALL & 2019 \\
\hline$[64]$ & AI in college English teaching & 2019 \\
\hline$[18]$ & Feasibility of chatbot & 2019 \\
\hline$[65]$ & $\mathrm{AI}$ in $5 \mathrm{G}$ technology & 2018 \\
\hline$[66]$ & AI trends in education & 2018 \\
\hline$[10]$ & AIED in English as a ESL classroom & 2018 \\
\hline$[67]$ & Trends in second language learning and teaching & 2018 \\
\hline$[68]$ & Impact of AI on learning, teaching, and education & 2018 \\
\hline$[15]$ & Machine learning in education & 2018 \\
\hline$[14]$ & AI for adaptive educational systems & 2017 \\
\hline$[11]$ & AI in college English teaching & 2017 \\
\hline$[16]$ & Bank chat BOT & 2017 \\
\hline$[69]$ & AI on teaching and learning in higher education & 2017 \\
\hline$[70]$ & Designing and practice of a college English teaching & 2017 \\
\hline [38] & English teachers' classroom teaching ability system based on AI & 2016 \\
\hline$[44]$ & Intelligent tutoring systems in e-learning & 2016 \\
\hline [45] & Tutoring system for teaching grammar English tenses & 2016 \\
\hline [6] & Distance learning of visually impaired people & 2016 \\
\hline [9] & Intelligent virtual environment for improving speaking and listening & 2016 \\
\hline
\end{tabular}


TABle 1: Continued.

\begin{tabular}{lcc}
\hline Reference no & Method & Year \\
\hline$[71]$ & On the track of AI & 2016 \\
{$[72]$} & E-learning using AI & 2015 \\
{$[25]$} & E-learning experience with AI-supported software & 2015 \\
{$[29]$} & College English teaching information based on AI & 2013 \\
{$[32]$} & The AI-based distance education system & 2013 \\
{$[24]$} & Computer-assisted learning & 2012 \\
{$[23]$} & Computer-based activities on iranian high-schools students' attitudes \\
{$[22]$} & Adaptive intelligent tutoring systems for e-learning systems & 2011 \\
{$[27]$} & Adaptive user interface for e-learning using ANN & 2010 \\
{$[34]$} & A personalized context-aware ubiquitous learning system & 2010 \\
{$[73]$} & Ambient intelligence & 2010 \\
{$[74]$} & Serious use of a serious game for language learning & 2009 \\
{$[75]$} & AI and second language learning & 2007 \\
{$[41]$} & Computer technology in second language acquisition & 2007 \\
{$[46]$} & Tutoring system for deaf learners of written English & 2006 \\
\hline
\end{tabular}



Figure 1: Publication type and subject areas with a total of materials published.

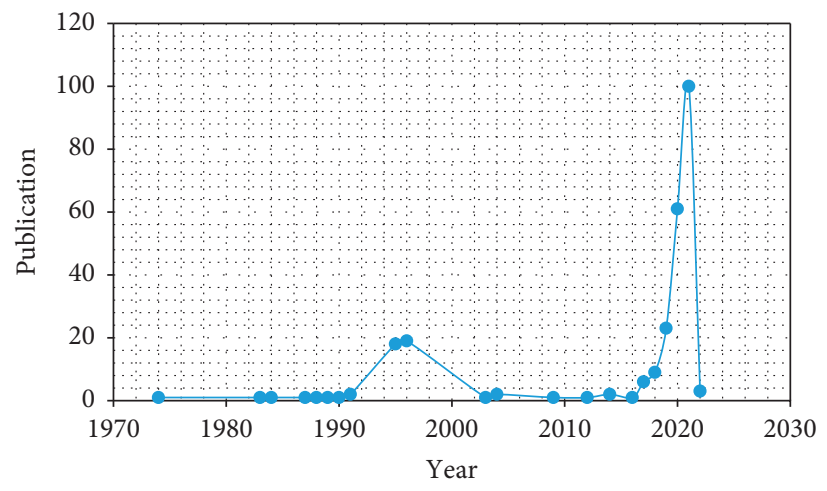

FIGURE 2: Materials published in the given years. 


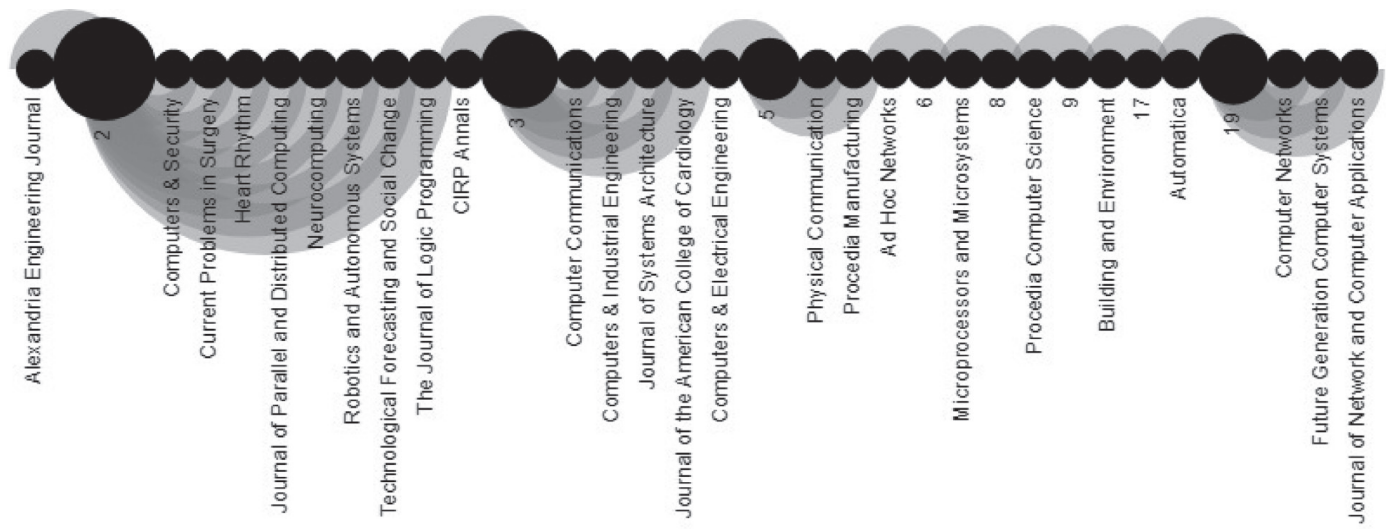

FIgUre 3: Publication titles with materials published.

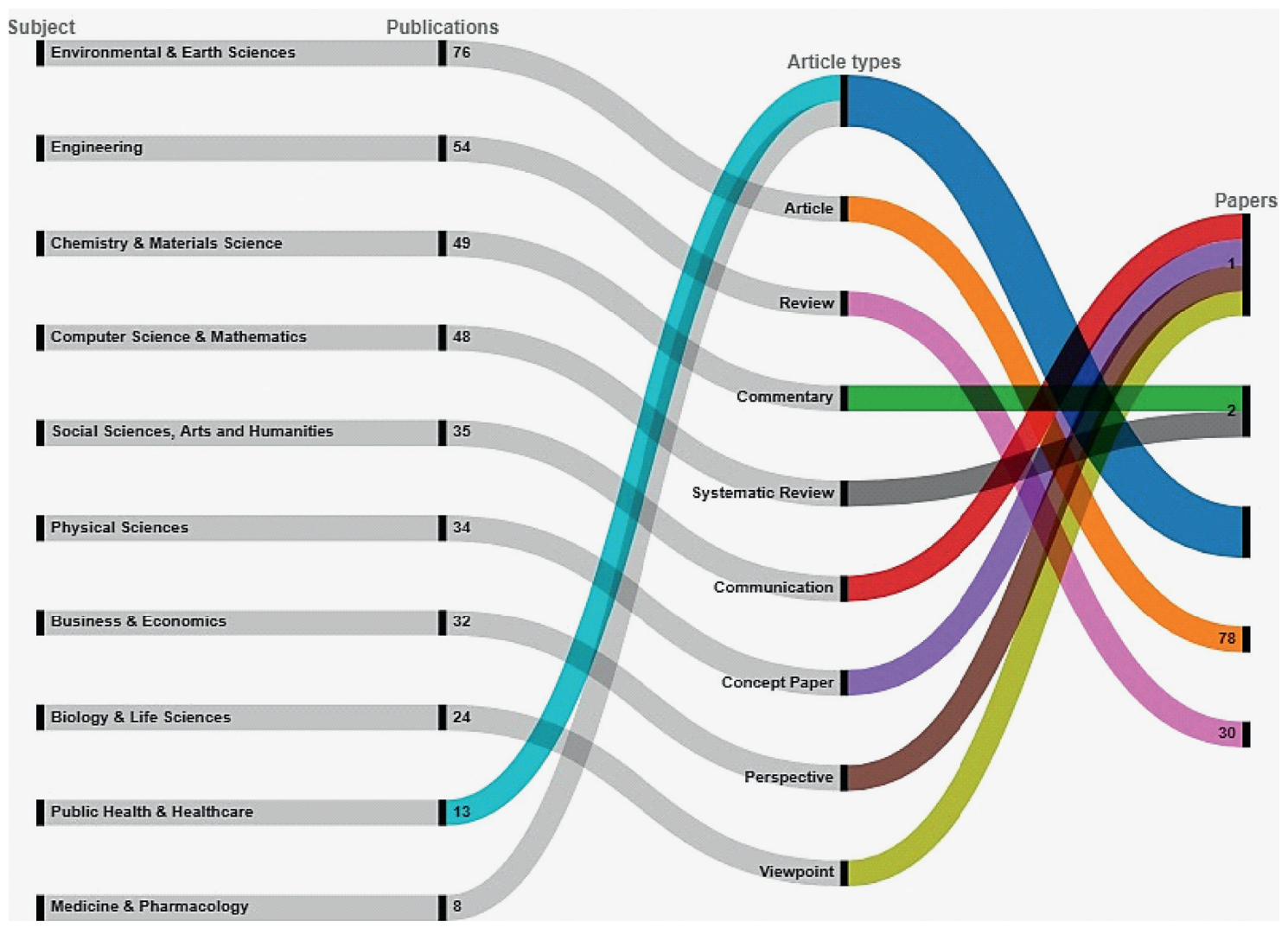

FIgURE 4: Subject, article types, and publications.

\section{Role of 5G Network Technology and Artificial Intelligence for English Situational Teaching in Higher Studies}

Vijayakumar et al. [42] have proposed a study to make a chatbot for the college to lessen the burden from human staff. With the help of the proposed system, there will be no need to deliver data to different sections but will store in a database in a single place. The system will work based on keywords entered by the user and will provide them with the information as matched with the given words. The students can access any kind of information at any time with the usage of the proposed chatbot. With the planned system, the overall working of college departments and students is improved and organized. The system is built-in Python along with natural language processing, and MySQL is used as data storage. Wang [43] has presented an overview of applications and advancements of artificial intelligence in daily life and the novelty and development brought by AIbased systems in teaching the English language. The implementation of AI in the English classroom has made the teaching and learning process more optimized and interactive. Students are now able to learn English with high intelligence and a personalized atmosphere. With the 


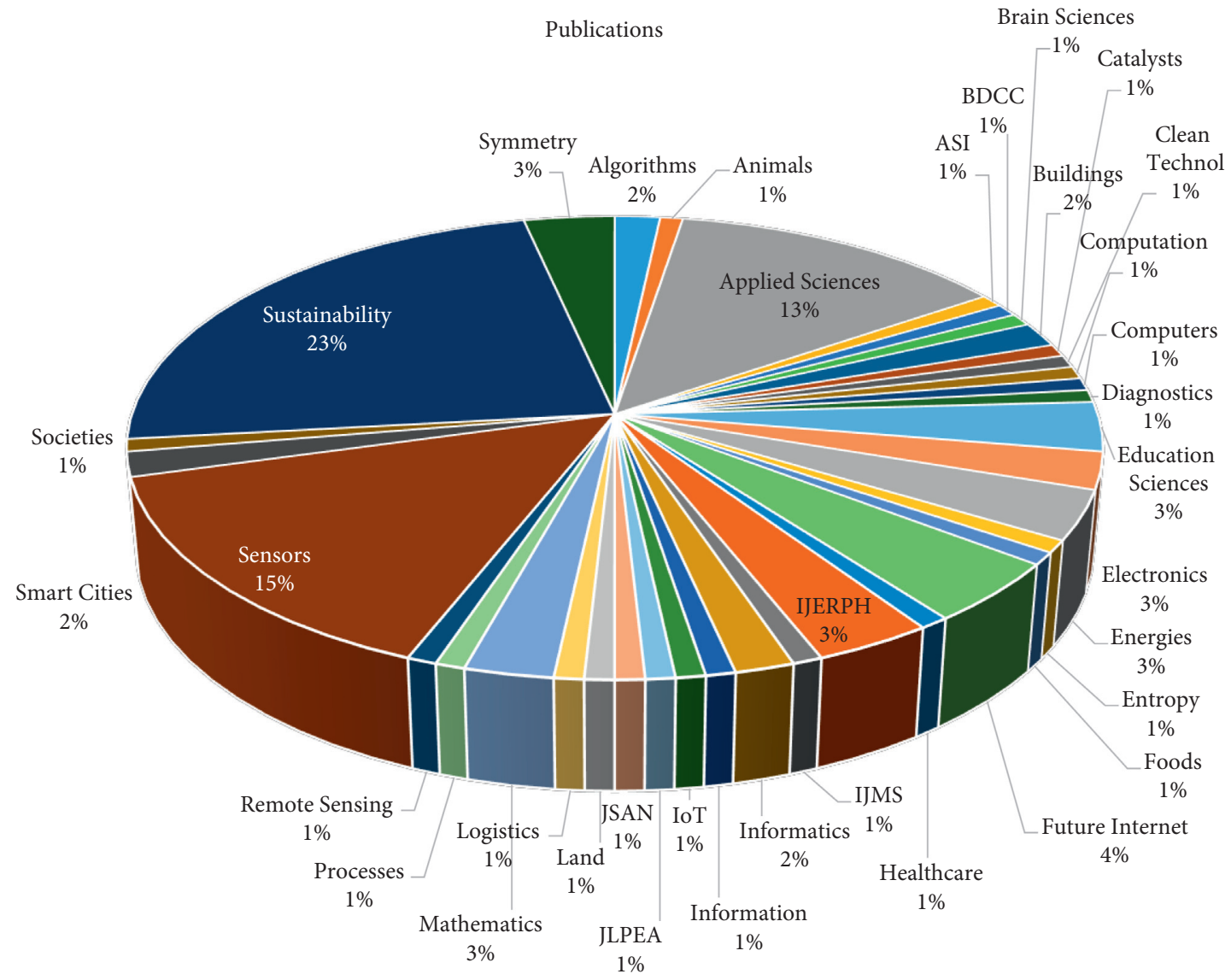

FIGURE 5: Journals with publications.

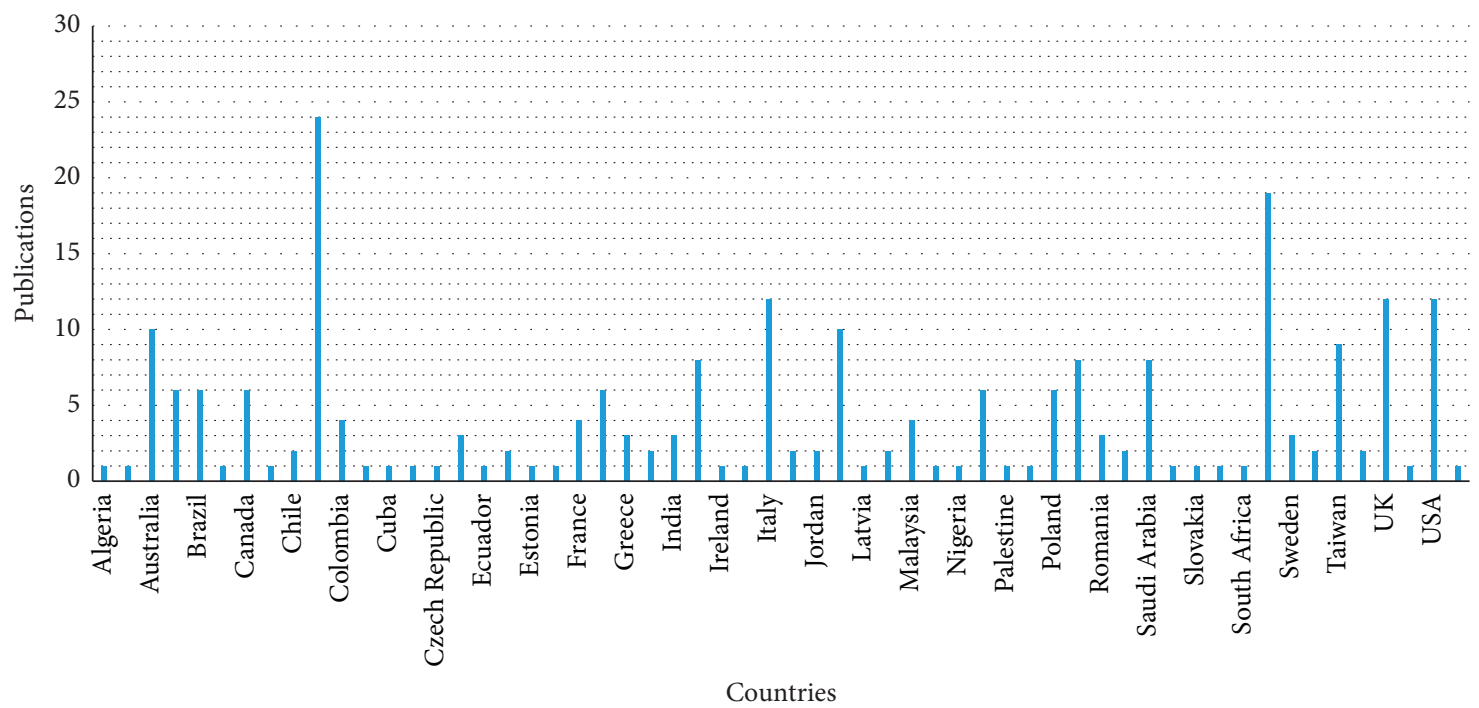

Figure 6: Counties and publications.

advancement in computer-assisted systems and the Internet, the AI-based system is now replacing human teachers in the classroom. The teachers are required to assimilate the new and advanced technologies into the teaching process and curriculum. With the combination of these, the English learning process can be made more productive and mature.
Dasic et al. [44] have proposed a study to dig out the applications and improvement and the usability of ITS in the learning methods of a new era. The online learning model is the combination of recent advancements in information technology and education. ITS usage in e-learning is accepted as very interactive and practical and is very helpful in 


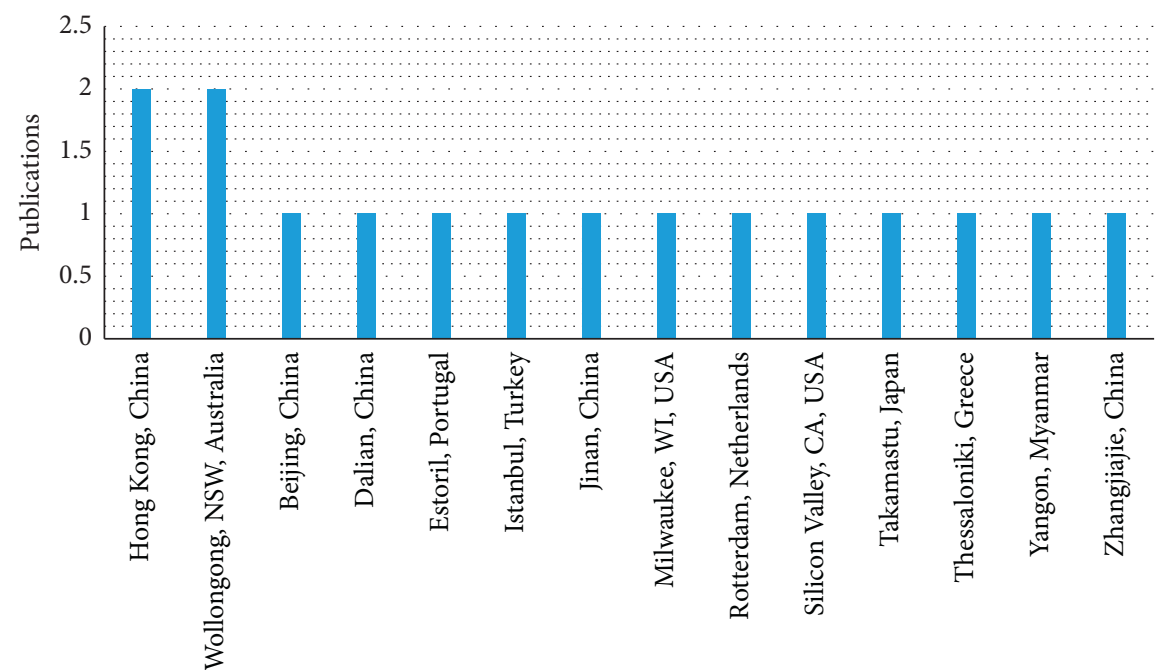

Conference location

FIgURE 7: Conference location with publications.

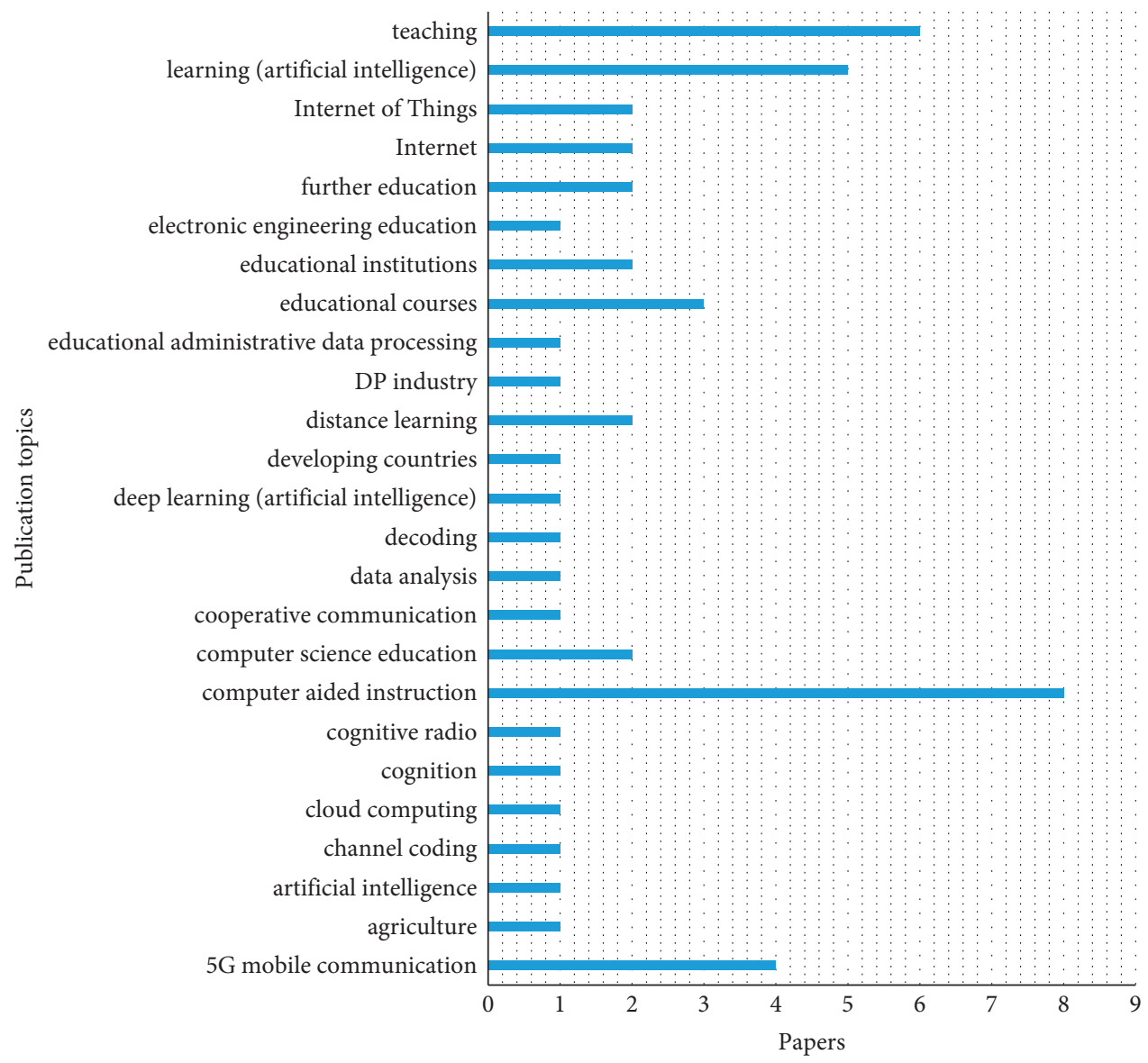

FIgURE 8: Publication topics in the given library.

making individualized learning possible. They are based on artificial intelligence and machine learning; hence, they can make effective strategies for personalized learning and thus keep the self-esteem of a learner. They are helpful to the students in correcting and providing suggestions related to their knowledge. With the implementation of AI algorithms, intelligent tutoring systems can solve any difficulty in teaching and learning. Alhabbash et al. [45] have proposed an intelligent tutoring system for the learners of English grammar. The students will be able to learn English language 


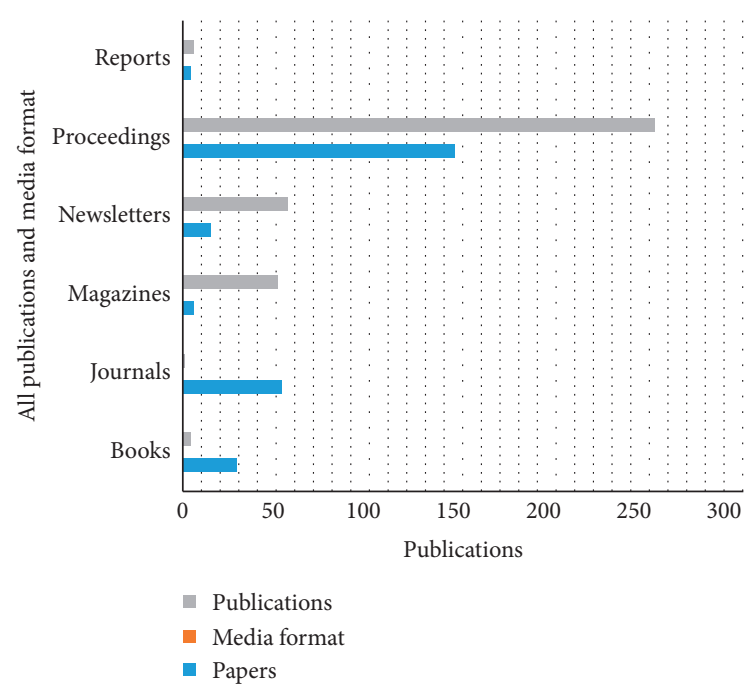

FIgURE 9: All publications, media format, and total papers.

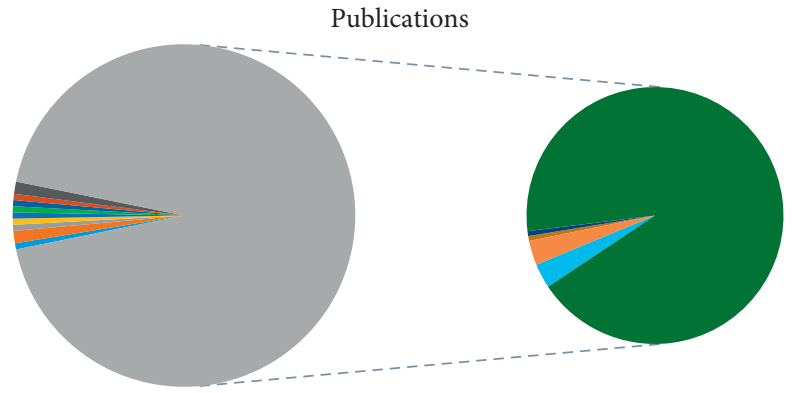
- Abstract
- Survey
- Index
Editorial
- Opinion
- Monograph
- Short Paper
- Prefatory
- Column
Extended Abstract
Introduction
- Note
- Poster
- Research Article

Figure 10: Types of contents.

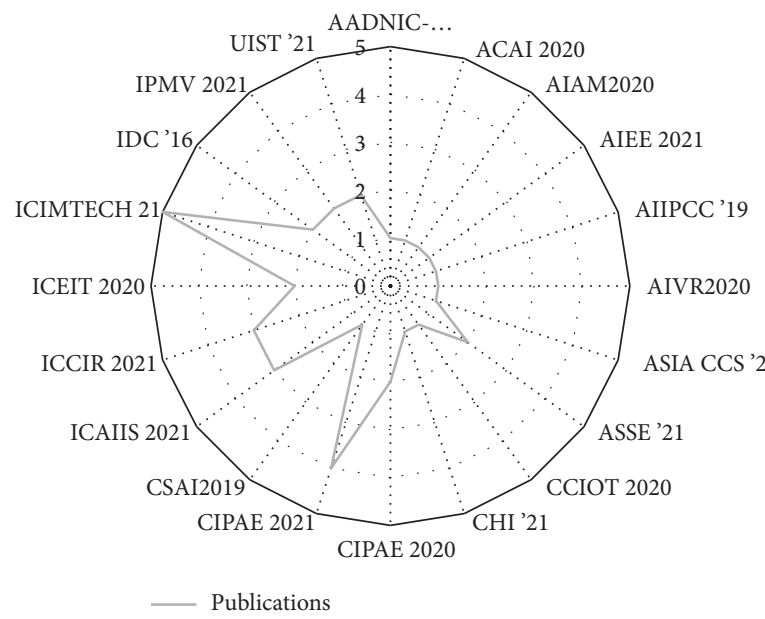

FIGURE 11: Conference events and publications. 


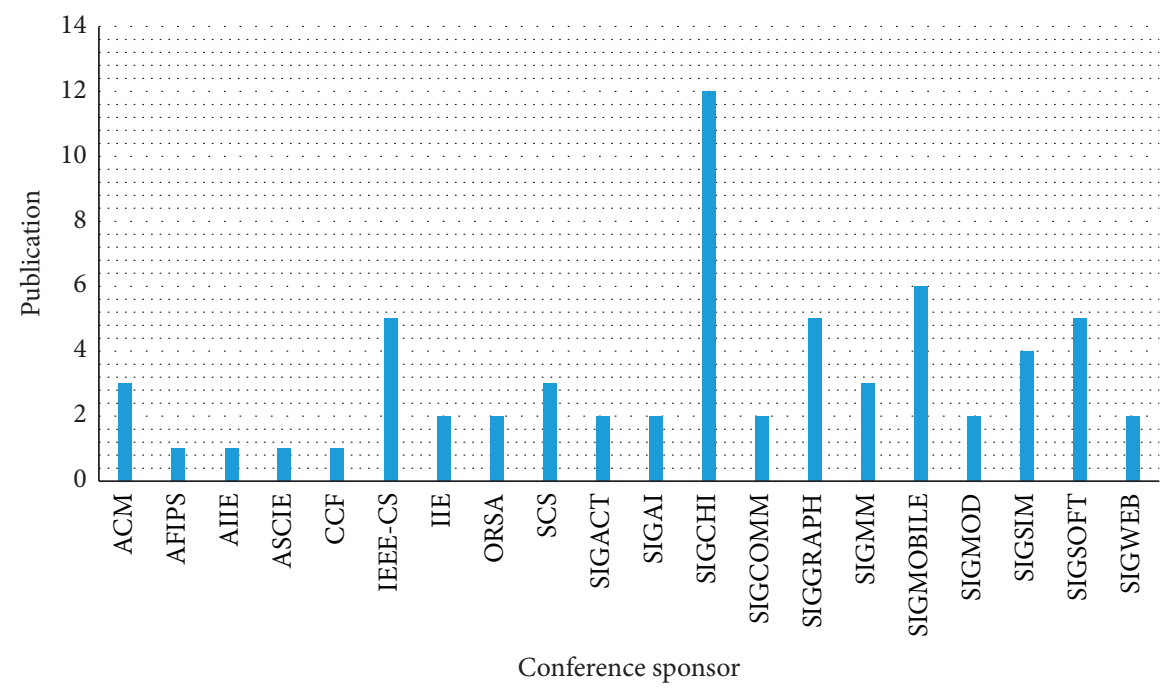

FIgURE 12: Conference events and papers.

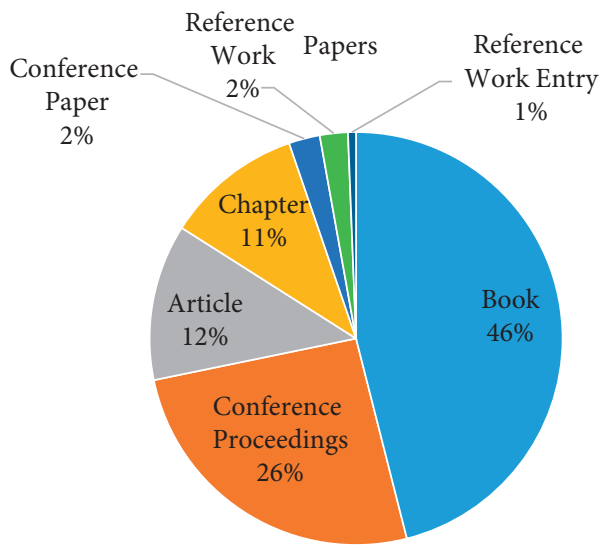

Figure 13: Article types and publications.

grammar in a straightforward and relaxed environment. The proposed approach can generate exercises related to each topic to check the students' skills in a particular section of grammar. It is based on a personalized learning atmosphere and can be used by every student independently. An experiment was performed with a group of students to check the performance of the intelligent tutoring system. The experiment's findings show that the students are in favor of the proposed approach, and their grammar has been improved and developed with the system.

Michaud et al. [46] have presented a sample of a device to improve and advance the writing skills of deaf students in school and college who are more comfortable with ASL than English. The system can take input from the students in written form and then examine that text for the syntax errors and allow the students to create possible solutions to correct the mistakes. The students are provided with constant feedback by the system and a comfortable, peaceful environment. The system is used for the learning purposes of the user and can analyze both the ASL and English language of the users. Baker et al. [47] have proposed a study to find out the reliability and practicability of intelligent tutoring systems to develop and increase the vocabulary and expertise of the English language of the students. About 217 students admitted to the English taught program were examined with the intelligent tutoring system. The analysis revealed that students using ITS have improved and developed vocabulary compared to other students. In the opinion of the students, it is exciting and creative to learn with ITS. The teachers are also in favor of the proposed system and accept the system as very effective and fruitful for the learners. The results show that the intelligent system can be used in the classroom to increase the productivity of the teaching and learning process. Terzopoulos and Satratzemi [48] have proposed a study to analyze the abilities and developments in education by artificial intelligence and natural language processingbased intelligent devices. With the use of AI and NLP, these devices can communicate and interact with the user in human-understandable languages. For providing and assisting disabled people, these voice assistants are proved to be very effective and game-changers. They can lessen the burden from the teacher and perform some functional tasks 


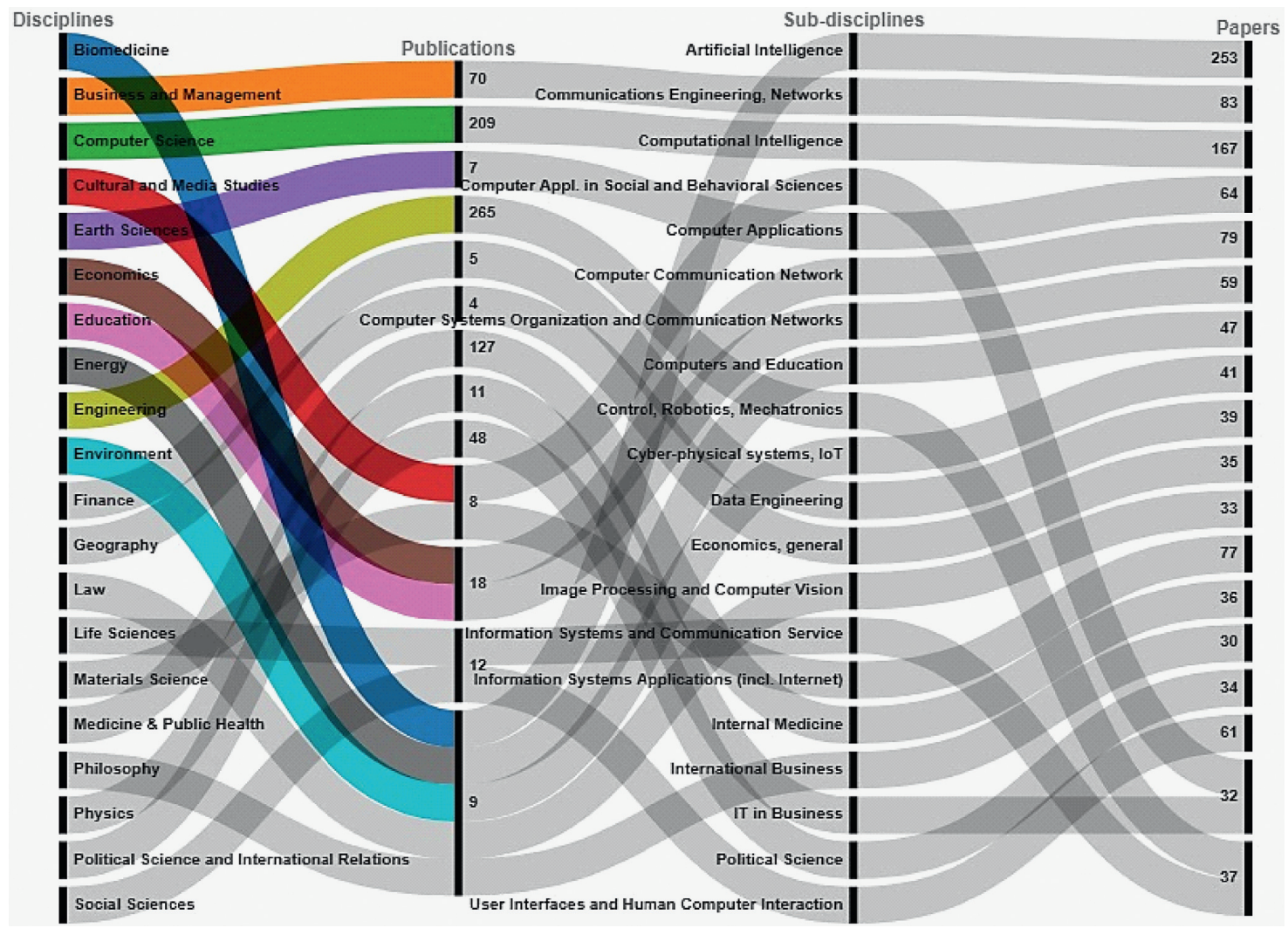

FIGURE 14: Details of disciplines, subdisciplines, and publications.

like assessment, quizzes, and interaction with the students in place of a teacher. However, one of the main disadvantages and matter of concern is that these devices cannot speak many languages. There is a need for proper and organized practice for teachers to use these voice assistants in the classroom. Junaidi et al. [49] have proposed a study to determine the productivity and impacts of AI-based applications in learning English as a foreign language. For this study, Lyra Virtual Assistant (LVA) is selected due to its simplicity in usage, being cheap, and improving students' pronunciation. An experiment was performed with two groups of students of the seventh class. The analysis shows that the students using the LVA have demonstrated significant improvement and development compared to the other learners. Using the proposed system, the students can achieve high-quality speaking skills and the system is very effective in improving the conversation power of students. The teachers should encourage the students the usage of computer-assisted devices in learning foreign languages. Parab [50] has proposed a study to show the effectiveness and improvement in the learning process of human teachers compared to AI-based intelligent systems. It was found that lack of human communication is a vital problem in computer-assisted teachers. AI and NLP-based machines should not replace human teachers but should be used for the help of a human to lessen the workload from a teacher. By making the other routine works of teachers automatic, they will be able to focus and concentrate on the skills and knowledge of the students. In short, the improvement and productivity in the performance of students can be brought only with the help of a human teacher. Voice assistants can be used to relieve the teacher in their daily routines. The proposed study has considered searching the famous libraries including ScienceDirect, ACM, MDPI, Springer, and IEEE for the search process. Table 1 briefly describes the methods used so far related to the proposed research.

The publication type and subject areas with a total of materials published in the ScienceDirect library are shown in Figure 1.

The materials published in the given year are presented in Figure 2.

The publication titles along with the materials are given in Figure 3.

The subject, article types, and publications in the MDPI library are shown in Figure 4.

The category of journals is given in Figure 5.

The publications along with the countries are given in Figure 6.

Figure 7 describes the conference location with a total of publications in the IEEE library.

The publication topics are shown in Figure 8.

All publications and media formats with a total of papers in the ACM library are shown in Figure 9.

The content types are presented in Figure 10.

The conference events and publications are given in Figure 11.

The conference sponsors and papers are given in Figure 12. 
The article types with publications in the Springer library are depicted in Figure 13.

Figure 14 displays the details of the disciplines, subdisciplines, and publications.

\section{Conclusion}

Intelligent and human-like machines and systems have enabled modern-day society by running daily life operations. This is done due to the advancements and growth in the field of AI. Diverse applications of the machine are used in different areas like automatic vehicles, healthcare, and complex decision-making and at a similar time used in educational institutes. The use of AI-based systems and the Internet has carried out revolutions in the field of education for both teachers and students. With the online learning platforms grounded on AI techniques, 5G has modernized the teaching and learning approaches by charming and quicker access to educational content. Students of foreign languages, particularly English learners, can now use chatbots and intelligent tutoring systems to learn and practice their speaking and listening skills both offline and online. With the implementation of computers, students can now enhance their language skills by exchanging information with AI-based agents in place of native speakers to evade any anxiety and worry. With the assistance of digital technology, it is effortless and valuable to improve English ability. To achieve the goal of English teaching, teachers should use AIbased methods in the classrooms. With the help of intelligent assistants for the daily workload of a teacher, it will be able to deliberate entirely on the language learning and skills of the students. This study has offered a thorough impression of the starring role of $5 \mathrm{G}$ and AI for English situational teaching in higher studies for the issues of modern learning and the use of technology. The search process and results are assembled and presented with different details of the research area.

\section{Data Availability}

No data were used to study support this study.

\section{Conflicts of Interest}

The authors have no conflicts of interest.

\section{References}

[1] J. Lee and D. Kim, "A study on innovation in university education: focusing on 5G mobile communication," in Proceedings of the 2020 IEEE 17th Annual Consumer Communications \& Networking Conference (CCNC), pp. 1-4, Las Vegas, NV, USA, January 2020.

[2] R. S. Al-Maroof, I. Akour, R. Aljanada et al., "Acceptance determinants of $5 \mathrm{G}$ services," International Journal of Data and Network Science, vol. 5, no. 4, pp. 613-628, 2021.

[3] X. Lei, "The research on optimization strategy of college English teaching mode based on 5G technology and artificial intelligence technology," in Proceedings of the 2020 International Conference on Virtual Reality and Intelligent Systems (ICVRIS), pp. 869-872, Zhangjiajie, China, July 2020.
[4] Y. Gao, "A survey study on the application of modern educational technology in English major college teaching in the age of 5G communication," Theory and Practice in Language Studies, vol. 11, no. 2, pp. 202-209, 2021.

[5] A. Islam and M. Hasan, "The effectiveness of mobile assisted language learning (MALL) on ESL listening skill," Nobel: Journal of Literature and Language Teaching, vol. 11, no. 2, pp. 188-202, 2020.

[6] G. A. Samigulina and A. Shayakhmetova, "Smart-system of distance learning of visually impaired people based on approaches of artificial intelligence," Open Engineering, vol. 6, no. $1,2016$.

[7] Y. Chung and J.-R. Kim, "Is artificial intelligence(AI) lecturer acceptable for adult learners in distance education?: an exploratory study on a cyber university, South Korea," The Journal of Internet Electronic Commerce Resarch, vol. 20, no. 2, pp. 65-81, 2020.

[8] H. Obari and S. Lambacher, "Improving the English skills of native Japanese using artificial intelligence in a blended learning program," CALL and Complexity-Short Papers from Eurocall 2019, pp. 327-333, Research-Publishing, 2019.

[9] K. Hassani, A. Nahvi, and A. Ahmadi, "Design and implementation of an intelligent virtual environment for improving speaking and listening skills," Interactive Learning Environments, vol. 24, no. 1, pp. 252-271, 2016.

[10] N. Keerthiwansha, "Artificial intelligence education (AIEd) in English as a second language (ESL) classroom in Sri Lanka," International Journal of Conceptions on Computing and Information Technology, vol. 6, no. 1, pp. 31-36, 2018.

[11] D. Zhu, "Analysis of the application of artificial intelligence in college English teaching," Advances in Intelligent Systems Research, vol. 134, pp. 235-237, 2017.

[12] E. Adamopoulou and L. Moussiades, "Chatbots: history, technology, and applications," Machine Learning with Applications, vol. 2, Article ID 100006, 2020.

[13] C. W. Okonkwo and A. Ade-Ibijola, "Chatbots applications in education: a systematic review," Computers \& Education: Artificial Intelligence, vol. 2, Article ID 100033, 2021.

[14] K. Almohammadi, H. Hagras, D. Alghazzawi, G. Aldabbagh, and S. C. Research, "A survey of artificial intelligence techniques employed for adaptive educational systems within e-learning platforms," Journal of Artificial Intelligence and Soft Computing Research, vol. 7, no. 1, pp. 47-64, 2017.

[15] D. Kučak, V. Juričić, and G. Đambić, "Machine learning in education-A survey of current research trends," Intelligent Manufacturing \& Automation, vol. 29, 2018.

[16] C. S. Kulkarni, A. U. Bhavsar, S. R. Pingale, and S. Kumbhar, "Bank Chat BOT-an intelligent assistant system using NLP and machine learning," International Research Journal of Engineering and Technology, vol. 4, no. 5, pp. 2374-2377, 2017.

[17] O. Nalyvaiko and A. Maliutina, "Use of chatbots in the educational process of a higher education institution," Scientific Notes of the Pedagogical Department, vol. 2021, no. 48, 2021.

[18] M. Arain, M. A. Memon, S. Bhatti, and M. Arain, "Feasibility of chatbot for mehran UET examination department," Review of Information Engineering and Applications, vol. 6, no. 2, pp. 17-28, 2019.

[19] M.-H. Hsu, P.-S. Chen, and C.-S. Yu, "Proposing a taskoriented chatbot system for EFL learners speaking practice," Interactive Learning Environments, pp. 1-12, 2021.

[20] J. Petrovic and M. Jovanovic, "Conversational agents for learning foreign languages--a survey," in Proceedings of the International Scientific Conference on Information Technology and Data Related Research, Belgrade, Serbia, November 2020. 
[21] S. Noviyanti, "Artificial intelligence (AI)-Based pronunciation checker: an alternative for independent learning in pandemic situation," Journal of English Language Teaching in Foreign Language Context, vol. 5, no. 2, Article ID 162, 2020.

[22] P. Phobun and J. Vicheanpanya, "Adaptive intelligent tutoring systems for e-learning systems," Procedia-Social and Behavioral Sciences, vol. 2, no. 2, pp. 4064-4069, 2010.

[23] M. Rahimi and K. S. Fatemeh Hosseini, "The impact of computer-based activities on Iranian high-school students' attitudes towards computer-assisted language learning," Procedia Computer Science, vol. 3, pp. 183-190, 2011.

[24] A. Shafaei, "Computer assisted learning: a helpful approach in learning English," Frontiers of Language and Teaching, vol. 3, pp. 108-115, 2012.

[25] U. Kose and A. Arslan, "E-learning experience with artificial intelligence supported software: an international application on English language courses," E-journal of UDEEEWANAUnited Distance Education for Eastern Europe western Asia Northern Africa, vol. 1, no. 3, pp. 61-75, 2015.

[26] I. Azzi, A. Jeghal, A. Radouane, A. Yahyaouy, H. Tairi, and I. Technologies, "A robust classification to predict learning styles in adaptive E-learning systems," Education and Information Technologies, vol. 25, no. 1, pp. 437-448, 2020.

[27] S. Kolekar, S. Sanjeevi, and D. S. Bormane, "The framework of an adaptive user interface for E-learning environment using artificial neural network," in Proceedings of the 2010 International Conference on E-Learning, E-Business, Enterprise Information Systems, \& E-Government, pp. 65-69, Las Vegas, NV, USA, July 2010.

[28] C. Meng-Yue, L. Dan, and W. Jun, "A study of college English culture intelligence-aided teaching system and teaching pattern," English Language Teaching, vol. 13, no. 3, pp. 77-83, 2020.

[29] X. Yuan, "Design of college English teaching information platform based on artificial intelligence technology," Journal of Physics: Conference Series, vol. 1852, no. 2, Article ID 022031, 2021.

[30] M. Sun and Y. Li, "Eco-Environment construction of English teaching using artificial intelligence under big data environment," IEEE Access, vol. 8, pp. 193955-193965, 2020.

[31] Y. Che, C. Sivaparthipan, and J. Alfred Daniel, "Human-computer interaction on IoT-based college physical education," Arabian Journal for Science and Engineering, pp. 1-13, 2021.

[32] V. Nabiyev, H. Karal, S. Arslan, A. K. Erumit, and C. Ayça, "An artificial intelligence-based distance education system," Artimat, vol. 14, no. 2, pp. 81-98, 2013.

[33] H. Dong and S. Tsai, "An empirical study on application of machine learning and neural network in English learning," Mathematical Problems in Engineering, vol. 2021, Article ID 8444858, 9 pages, 2021.

[34] C.-M. Chen and Y.-L. Li, "Personalised context-aware ubiquitous learning system for supporting effective English vocabulary learning," Interactive Learning Environments, vol. 18, no. 4, pp. 341-364, 2010.

[35] A. F. Muhammad, D. Susanto, A. Alimudin, F. Adila, M. H. Assidiqi, and S. Nabhan, "Developing English conversation chatbot using dialogflow," in Proceedings of the 2020 International Electronics Symposium (IES), pp. 468-475, Surabaya, Indonesia, September 2020.

[36] M.-C. Sung, "Pre-service primary English teachers' AI chatbots," Lanaguage Research, vol. 56, no. 1, pp. 97-115, 2020.

[37] Q. Liu, "The effectiveness of internet-based Multimedia assisted language learning (IB-MALL) in improving students'
English proficiency under sino-foreigner cooperative education context from students' perspectives," Master Thesis, 2019.

[38] Y. Cuiye, "The construction of English teachers' classroom teaching ability system based on artificial intelligence," Revista Ibérica de Sistemas e Tecnologias de Informação, vol. 18B, Article ID 94, 2016.

[39] S. Huang, "Design and development of educational robot teaching resources using artificial intelligence technology," International Journal of Emerging Technologies in Learning, vol. 15, no. 5, 2021.

[40] A. Liu and D. Kong, "A study on the diversified college english teaching mode based on artificial intelligence," in Proceedings of the E3S Web of Conferences, vol. 251, Xiamen, China, 2021.

[41] C.-C. Lai and W. Kritsonis, "The advantages and disadvantages of computer technology in second language acquisition," National Journal For Publishing And Mentoring Doctoral Student Research, vol. 3, no. 1, 2006.

[42] R. Vijayakumar, B. Bhuvaneshwari, S. Adith, and M. Deepika, "AI based student bot for academic information system using machine learning," International Journal of Scientific Research in Computer Science, Engineering and Information Technology, vol. 5, no. 2, pp. 590-596, 2019.

[43] X. Wang, "College English teaching innovation under artificial intelligence," in Proceedings of the Sixth International Conference on Information Management and Technology, pp. 1-4, New York, NY, USA, August 2021.

[44] P. Dašić, J. Dašić, B. Crvenković, and V. Šerifi, "A review of intelligent tutoring systems in e-learning," Annals of the University of Oradea Fascicle of Management and Technological Engineering, vol. 15, pp. 85-89, 2016.

[45] M. I. Alhabbash, A. O. Mahdi, and S. Naser, "An Intelligent Tutoring System for Teaching Grammar English Tenses," European Academic Research, vol. 4, no. 9, 2016.

[46] L. N. Michaud, K. F. McCoy, and C. A. Pennington, "An intelligent tutoring system for deaf learners of written English," in Proceedings of the fourth international ACM conference on Assistive technologies, pp. 92-100, Arlington, VA, USA, January 2000.

[47] D. L. Baker, H. Ma, P. Polanco et al., "Development and promise of a vocabulary intelligent tutoring system for Second-Grade Latinx English learners," Journal of Research on Technology in Education, vol. 53, no. 2, pp. 223-247, 2021.

[48] G. Terzopoulos and M. Satratzemi, "Voice assistants and artificial intelligence in education," in Proceedings of the 9th Balkan Conference on Informatics, pp. 1-6, New York, NY, USA, September 2019.

[49] J. Junaidi, B. Hamuddin, K. Julita, F. Rahman, and T. Derin, "Artificial intelligence in EFL context: rising students' speaking performance with Lyra virtual assistance," International Journal of Advanced Science and Technology, vol. 29, no. 5, pp. 6735-6741, 2020.

[50] A. K. Parab, "Artificial intelligence in education: teacher and teacher assistant improve learning process," International Journal for Research in Applied Science \& Engineering Technology, vol. 8, 2020.

[51] Z. Sun, M. Anbarasan, and D. Praveen Kumar, "Design of online intelligent English teaching platform based on artificial intelligence techniques," Computational Intelligence, vol. 37, no. 3, pp. 1166-1180, 2021.

[52] H. Du, "An English network teaching method supported by artificial intelligence technology and WBIETS system," Scientific Programming, vol. 2021, Article ID 8783899, 9 pages, 2021. 
[53] R. Aljohani, "Teachers and students' perceptions on the impact of artificial intelligence on English language learning in Saudi arabia," Journal of Applied Linguistics and Language Research, vol. 8, no. 1, pp. 36-47, 2021.

[54] S. Wollny, J. Schneider, D. Di Mitri, J. Weidlich, M. Rittberger, and H. Drachsler, "Are we there yet?-A systematic," Literature Review on Chatbots in Education, vol. 4, 2021.

[55] A. Guo and C. Yuan, "Network intelligent control and traffic optimization based on SDN and artificial intelligence," Electronics, vol. 10, no. 6, Article ID 700, 2021.

[56] J. Kim, K. Merrill, K. Xu, and D. D. Sellnow, "My teacher is a machine: understanding students' perceptions of AI teaching assistants in online education," International Journal of $\mathrm{Hu}$ man-Computer Interaction, vol. 36, no. 20, pp. 1902-1911, 2020.

[57] Y.-J. Wu, P.-C. Hwang, W.-S. Hwang, and M. Cheng, “Artificial intelligence enabled routing in software defined networking," Applied Sciences, vol. 10, no. 18, Article ID 6564, 2020.

[58] N. Haristiani, "Artificial Intelligence (AI) chatbot as language learning medium: an inquiry," Journal of Physics: Conference Series, vol. 1387, no. 1, Article ID 012020, 2019.

[59] X. Lu, "An empirical study on the artificial intelligence writing evaluation system in China CET," Big Data, vol. 7, no. 2, pp. 121-129, 2019.

[60] R. Wang, "Research on artificial intelligence promoting English learning change," in Proceedings of the 3rd International Conference on Economics and Management, Education, Humanities and Social Sciences (EMEHSS 2019), Suzhou, China, January 2019.

[61] Y. Hou, "foreign language education in the era of artificial intelligence," in Proceedings of the International conference on Big Data Analytics for Cyber-Physical-Systems, pp. 937-944, Shenyang, China, December 2019.

[62] O. Zawacki-Richter, V. I. Marín, M. Bond, and F. Gouverneur, "Systematic review of research on artificial intelligence applications in higher education-where are the educators?" International Journal of Educational Technology in Higher Education, vol. 16, no. 1, pp. 1-27, 2019.

[63] N. Kim, "A study on the use of artificial intelligence chatbots for improving English grammar skills," Journal of Digital Convergence, vol. 17, no. 8, pp. 37-46, 2019.

[64] X. Li, "The application and feasibility of artificial intelligence in college English teaching," in Proceedings of the 9th International Conference on Education and Social Science, Shenyang, China, March 2019.

[65] M. Cayamcela and W. Lim, "Artificial intelligence in 5G technology: a survey," in Proceedings of the 2018 International Conference on Information and Communication Technology Convergence (ICTC), pp. 860-865, Jeju, Republic of Korea, October 2018.

[66] M. Chassignol, A. Khoroshavin, A. Klimova, and A. Bilyatdinova, "Artificial Intelligence trends in education: a narrative overview," Procedia Computer Science, vol. 136, pp. 16-24, 2018.

[67] J. Kannan and P. Munday, "New trends in second language learning and teaching through the lens of ICT, networked learning, and artificial intelligence," Círculo de Lingüística Aplicada a la Comunicación, vol. 76, 2018.

[68] I. Tuomi, The Impact of Artificial Intelligence on Learning, Teaching, and Education, Publications Office of the European Union, Luxembourg City, Luxembourg, 2018.
[69] S. Popenici, S. Kerr, and P. Learning, "Exploring the impact of artificial intelligence on teaching and learning in higher education," Research and Practice in Technology Enhanced Learning, vol. 12, no. 1, pp. 22-13, 2017.

[70] S. Zou and T. Nanoscience, "Designing and practice of a college English teaching platform based on artificial intelligence," Journal of Computational and Theoretical Nanoscience, vol. 14, no. 1, pp. 104-108, 2017.

[71] N. Goksel Canbek and M. Mutlu, "On the track of artificial intelligence: learning with intelligent personal assistants," International Journal of Human Sciences, vol. 13, no. 1, pp. 592-601, 2016.

[72] A. Potode, P. Manjare, and I. T. Research, "E-learning using artificial intelligence," International Journal of Computer Science and Information Technology Research, vol. 3, no. 1, pp. 78-82, 2015.

[73] J. C. Augusto, L. I. Information, and C. Sciences, “Ambient intelligence: opportunities and consequences of its use in smart classrooms," Innovation in Teaching and Learning in Information and Computer Sciences, vol. 8, no. 2, pp. 53-63, 2009.

[74] W. I, "Serious use of a serious game for language learning," Johnson and Applications, vol. 158, Article ID 67, 2007.

[75] M. Dodigovic, "Artificial intelligence and second language learning: an efficient approach to error remediation," Language Awareness, vol. 16, no. 2, pp. 99-113, 2007. 